\title{
Studies on Thermal Stability, Shelf Life and Electrochemical Measurement of Methanol Extract of Air Dried Alchornea Laxiflora Leaves in Corrosion Prevention
}

\author{
Oluwafemi Lawrence Adebayo ${ }^{1,5, ~ *, ~ E m m a n u e l ~ F o l o r u n s o ~ O l a s e h i n d e ~}{ }^{2,3}$, Labunmi Lajide ${ }^{3}$, \\ Daniel Oloruntoba ${ }^{4}$, Morenike Grace Ajayi ${ }^{5}$ \\ ${ }^{1}$ Department of Chemical and Process Engineering, University of Strathclyde, Glasgow, United Kingdom \\ ${ }^{2}$ Department of Physical and Chemical Sciences, Elizade University, Ilara Mokin, Nigeria \\ ${ }^{3}$ Department of Chemistry, Federal University of Technology, Akure, Nigeria \\ ${ }^{4}$ Department of Metallurgical and Materials Engineering, Federal University of Technology, Akure, Nigeria \\ ${ }^{5}$ Department of Chemistry, College of Education, Ikere, Nigeria
}

Email address:

femtay41@yahoo.co.uk (O. L. Adebayo)

${ }^{*}$ Corresponding author

\section{To cite this article:}

Oluwafemi Lawrence Adebayo, Emmanuel Folorunso Olasehinde, Labunmi Lajide, Daniel Oloruntoba, Morenike Grace Ajayi. Studies on Thermal Stability, Shelf Life and Electrochemical Measurement of Methanol Extract of Air Dried Alchornea Laxiflora Leaves in Corrosion Prevention. American Journal of Materials Synthesis and Processing. Vol. 4, No. 2, 2019, pp. 68-74. doi: 10.11648/j.ajmsp.20190402.13

Received: July 25, 2019; Accepted: September 5, 2019; Published: November 22, 2019

\begin{abstract}
The aim of this study was to determine the thermal stability and shelf life of the extract together with the influence of extract concentration, temperature and $\mathrm{pH}$ variation of the acidic medium on the inhibition efficiency using $1.0 \mathrm{M}$ Sodium hydroxide. The dried plant samples were ground, sieved using $0.25 \mu \mathrm{m}$ and then extracted with methanol using maceration method. The phytochemical constituents were analyzed using appropriate methods. The phytochemicals detected were: Alkaloid, saponin, flavnoid, tannin, terpenoid, steroid and cardiac glycoside. Weight loss experiment was performed to ascertain the stability and shelf life of the extract at different storage temperature and time respectively while polarization experiment was used to study the behaviour of the extract on mild steel corrosion at varying concentration of the extract, $\mathrm{pH}$ and temperature of the acidic media. It was found that the stability of the extract inhibition efficiency was affected by the mode of storage and the inhibition efficiency decreases with increase in storage temperature of the extract. The life span of the extract was found to be 60 days from its production stage, after this, there was reduction in the inhibition efficiency of the extract. Moreso, the corrosion rate of the mild steel in $1.0 \mathrm{M} \mathrm{HCl}$, monitored by electrochemical measurement revealed that the corrosion rate decreases with increase in the $\mathrm{pH}$, decrease in temperature and increase in concentration of the extract in the acidic solution.
\end{abstract}

Keywords: Phytochemicals, Storage Temperature, Shelf Life, Solution $\mathrm{pH}$

\section{Introduction}

The major problem faced by the industries is the corrosion of metals and alloys particularly in acidic media. During metal pickling, cleaning, descaling and etching using hydrochloric acid, the acid however contributes to the corrosion of metal surface. A huge amount of money is wasted each year as a result of metallic corrosion which cumulates to an estimated loss of 276 billion USD or equivalent to 3.1 percent of the United States GDP [1]. It is estimated that with proper corrosion prevention technologies, about 25 to $30 \%$ of this loss could be avoided [1]. One of the best methods to reduce the rate of metallic corrosion is by the addition of inhibitors; even small concentrations can result in the decrease of the corrosion rate of the metal surface [2-8]. Several conditions must be fulfilled for the selection of a suitable inhibitor; (a) the cost and amount of the inhibitors, (b) long term toxicological effects on the environment and 
living species, (c) the inhibitor's availability and stability in the environment. It has been found that different organic compounds could be used as effective corrosion inhibitors during acid pickling process [9-11]. Literature survey reveals that organic compounds containing heteroatoms with high electron density such as phosphorus, nitrogen, sulfur, oxygen, with double or triple bonds in their structures are effective corrosion inhibitors due to their high tendency for adsorption on the metal solution interface [11-14], and the adsorption may take place by the possible four types: (a) due to electrostatic attraction between the charged molecules of inhibitors and charged metal surface (b) interaction of unshared electron pairs of the molecules with the metal surface (c) interaction of the presence of conjugated bonds $(\pi$ electron) in the compound with metal (d) adsorption may occur by the combination of (a) and (c) [15], as a result of adsorption and blocking the active surface sites, thus reducing the corrosion rate by: (a) slowing the anodic and/or cathodic reaction (b) slowing the diffusion of aggressive species to the metal surface and (c) decreasing the electrical resistance of the metal surface.

It has been confirmed that the compounds having both nitrogen and sulfur in their molecular structure have excellent corrosion inhibition ability compared to those containing only nitrogen or sulphur, moreover sulfur containing compounds have generally stronger corrosion inhibition ability compared to nitrogen containing compounds [16-21]. Also the quantum chemical calculation analysis proves that enhancement of electron donor ability causes higher corrosion inhibition efficiency as a result of the presence of sulfur compounds [21]. It has been reported that the adsorption properties of organic inhibitors mainly depend on some physicochemical properties of the molecules; the functional groups, possible steric effects, electronic density of donor atoms and the possible interaction of p-orbitals of the inhibitor with d-orbitals of the surface atoms, establish a degree of adsorption of organic inhibitor molecules on the solid surface and results into a barrier film for corrosion protection [22].

Literature study reveals a significant relationship between adsorption of organic compounds and corrosion inhibition process, as corrosion inhibition is a well-known surface phenomenon and adsorption is a function of degree of protection of the metal surface [23, 26]. These organic compounds have been used as corrosion inhibitors in the petroleum industry since 1950 s and in the concrete industry from the early 1990s [27]. The toxic nature of synthetic corrosion inhibitors has led to the search for their replacement using plant based corrosion inhibitors. In spite of the fact that a lot of plant materials have been investigated for corrosion inhibition and most of them have proven to have high corrosion inhibition efficiency, however, the investigation has been limited to the laboratory. Further, the mechanism of the reaction process and the characterization of the active constituents in the extract which are responsible for the corrosion inhibition still remains a mystery.

The plant leaf selected for this research work is air dried
Alchonea laxiflora leaves. The literature studies on the plant revealed that they have high phytochemical constituents [2830]. Furthermore, it has also been established that plants with high phytochemicals are good corrosion inhibitors and most of these materials are inexpensive, readily available, ecologically friendly and poses no threat to the environment [31-33]. Meanwhile the mode of drying and the effect of solvents used in extracting the leaf have been established in our previous research [34]. From our findings, it was established that the air dried portion of the leaf extracted with methanol has the highest inhibition efficiency. However, the thermal stability, shelf life and electrochemical measurement of methanol extract of the leaf for corrosion control is yet to be established. Thus, this research is designed to address this information gap.

\section{Materials and Experimental Methods}

\subsection{Materials}

The mild steel employed for this study was procured and the chemical composition was determined at University of Strathclyde, Glasgow, United Kingdom. The sheets were mechanically pressed cut to coupon of dimension $2.5 \times 2.5 \times$ $0.4 \mathrm{~cm}$. A small hole of about $5 \mathrm{~mm}$ diameter near the upper edge of the coupons was made and the coupons were suspended into the corrosive medium with the aid of glass hooks. The mild steel was polished with different grades of emery paper placed on struer polishing machine, washed with distilled water, dried under nitrogen gas and stored in moisture free desiccators prior to use [35-37]. The aggressive acidic solution of $1.0 \mathrm{M} \mathrm{HCl}$ was prepared by dilution of concentrated $\mathrm{HCl}$ with distilled water and all experiments were carried out in unstirred solutions and weighing was made using analytical weighing balance (Metler Toledo PB153). Other materials and equipment used include Alchornea laxiflora leaves, weighing balance, rotary evaporator, distilled water, beaker, measuring cylinder, paper tape and $1.0 \mathrm{M} \mathrm{NaOH}$.

\subsection{Preparation of Plant Sample}

Alchornea laxiflora leaves were obtained in the vicinity of Federal Polytechnic Ado, Ekiti State, Nigeria and were authenticated at the Department of Biology, College of Education, Ikere, Ekiti State, Nigeria. The fresh samples were washed and air-dried for one month. All dried plant materials were ground to powder and sieved to obtain fine particles. $20 \mathrm{~g}$ of the sample was soaked with methanol with continuous agitation for 72 hours. The filtrates were concentrated using rotary evaporator at $60^{\circ} \mathrm{C}$. The dried extracts were weighed and stored at room temperature.

\subsection{Determination of the Phytochemical Constituents}

Biochemical tests were done to check the presence and the quantity of different phytochemicals such as flavnoids, steroids, tannin, alkaloids, saponin, anthraquinone, cardiac glycosides, phytobalatin and terpenoid in the methanol 
extract of air dried Alchornea laxiflora leave and this was carried out by simple qualitative and quantitative methods [38-41].

\subsection{Thermal Stability}

Ten grams of the leaf sample was introduced into five different glass bottles. The samples were stored at different temperature of $-20^{\circ} \mathrm{C}, 0^{\circ} \mathrm{C}, 20^{\circ} \mathrm{C}, 40^{\circ} \mathrm{C}$ and $60^{\circ} \mathrm{C}$ for a period of two months before the corrosion inhibition studies was carried out using weight loss measurement.

\subsection{Shelf Life}

The shelf life of the methanol extract was evaluated at room temperature by comparing the inhibition efficiency of the freshly prepared extract with those prepared, stored and tested at an interval of thirty days for a period of one hundred and fifty days using weight loss measurement.

\subsection{Electrochemical Measurement}

Electrochemical measurement experiment was carried out on the methanol extract of air dried Alchornea laxiflora leaves by considering different concentration of the extract, $\mathrm{pH}$ and temperature of the acidic medium. The experiment was performed by using a polarization cell of one litter capacity. The cell consists of a reference electrode which is made up SCE, counter electrode (CE) that is made up of platinum electrode and the working electrode (WE) of mild steel. To prepare the working electrode, mild steel sample was obtained and carefully cut into many cylindrical electrodes. One of the working electrodes was polished using a struer polishing machine containing an emery paper, and obtained a mirror finish sample, washed with distilled water and dried under nitrogen gas.

\section{Results and Discussion}

\subsection{Phytochemical Screening}

The phytochemical screening test of the methanol extract was performed to detect the presence of bioactive components and their quantity in the extracts of air dried Alchornea laxiflora leaves. The results obtained and published in our earlier research are presented in Table 1 [34].

Table 1. Qualitative and Quantitative phytochemical screening of air dried Alchornea laxiflora leave extracted with methanol.

\begin{tabular}{lll}
\hline Phytochemicals (mg/g) & $\begin{array}{l}\text { Qualitative } \\
\text { phytochemical } \\
\text { screening }\end{array}$ & $\begin{array}{l}\text { Quantitative } \\
\text { phytochemical } \\
\text { screening }\end{array}$ \\
\hline Alkaloid & + & 7.91 \\
Flavnoid & +++ & 12.51 \\
Anthraquinone & - & - \\
Tannin & +++ & 16.07 \\
Terpenoid & ++ & 13.23 \\
Steroid & + & 5.36 \\
Saponin & +++ & 51.05 \\
Cardiac glycoside & ++ & 9.75 \\
Phytobatanin & - & - \\
\hline
\end{tabular}

\subsection{Thermal Stability}

The mode of storage of the extract affects its antioxidants activity on mild steel in acidic medium. The aim of this part of the research was to measure the stability of the extract when stored at different temperature values. As observed in Figure 1, the inhibition efficiency of the extract was nearly at par when it was stored at $-20^{\circ} \mathrm{C}$ and room temperature especially at higher concentration of the extract. Above the room temperature, the inhibition efficiency of the extract at different concentration decreased drastically. This decrease in inhibition efficiency of the extract with increase in storage temperature could be ascribed to the degradation of the phytochemical constituents which are responsible for the corrosion inhibition of mild steel in acidic medium. Similar findings have been observed by some researchers [42].

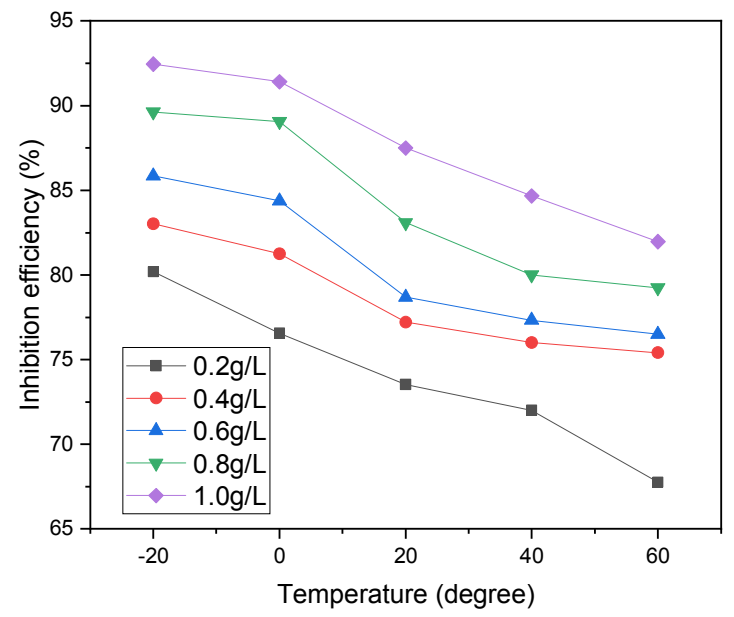

Figure 1. Effects of Storage Temperature on methanol extract of air dried Alchornea laxiflora leaves on its Inhibition efficiency.

Furthermore, due to the loss of the phytochemical constituents with increase in temperature, a plot of the weight loss of the mild steel against storage temperature (Figure 2) in the absence and presence of the extract at different concentration revealed that the weight loss of the mild steel increases with increase in temperature, although it was much more pronounced in the uninhibited solution than the inhibited solutions.

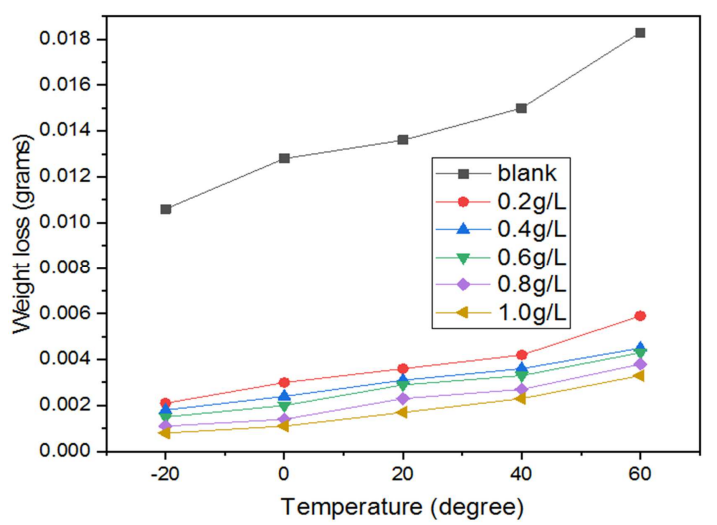

Figure 2. Plot of mild steel weight loss against storage temperature at different concentrations. 


\subsection{Shelf Life Study}

The result (Figure 3) obtained from the shelf life study at different concentrations of the extract revealed that the methanol extract considerably sustained its efficiency for a period of 60 days, after which a gradual decline was noticed between the period of 60 to 150 days. The reduction in the inhibition efficiency of the extract after the period of 60 day of storage may be attributed to some chemical reaction between the constituents which led to the non availability of the active groups that are responsible for adsorption on the mild steel surface. Due to this, the total surface of the mild steel that needs to be covered by extract active groups reduced, hence a reduction in the inhibition efficiency was observed [43].

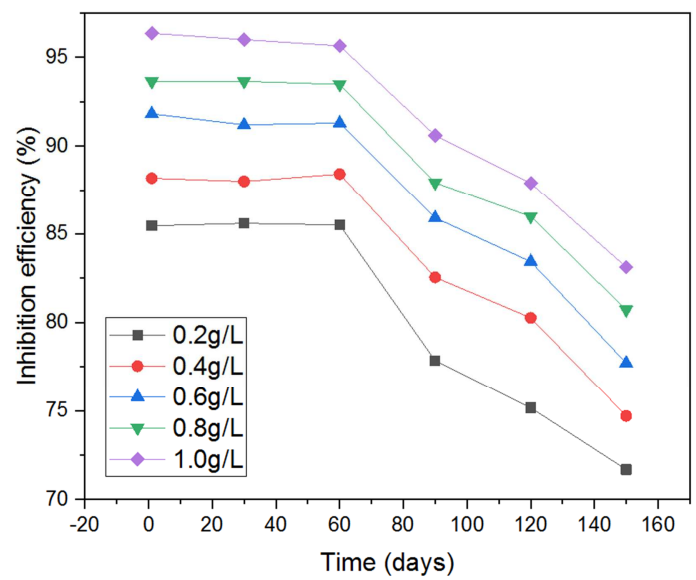

Figure 3. Variation of Methanol extract of Alchornea Laxiflora leaves Inhibition efficiency against its shelf life at different Concentrations.

\subsection{Electrochemical Measurement}

\subsection{1. $\mathrm{pH}$ Variation}

The $\mathrm{pH}$ is an important factor for metal corrosion in an acidic solution. In general, metals exhibit different corrosion behavior in acidic, neutral and alkaline media. The $\mathrm{pH}$ value of a solution can affect the reaction mechanism and of course can be directly involved in the reaction.

The effect of $\mathrm{pH}$ variation of acidic medium on corrosion rate of mild steel in the presence of $1.0 \mathrm{~g}$ of methanol extract was performed by using Tafel polarization measurement, which consists of the determination of Tafel curves. The Tafel plots of mild steel at various $\mathrm{pH}$ of the acidic solution at fixed concentration of the extracts are summarized in Figure 4 while the corrosion parameters obtained are shown in Table 2. From the result, it was observed that with the increase in $\mathrm{pH}$ of the acidic solution from 2 to 14 , both the anodic and cathodic current densities decreases. Although the marked positive shift in the corrosion potentials and the decrease in both anodic and cathodic current density with increase in $\mathrm{pH}$ indicates that the methanol extract acts as a mixed inhibitor.

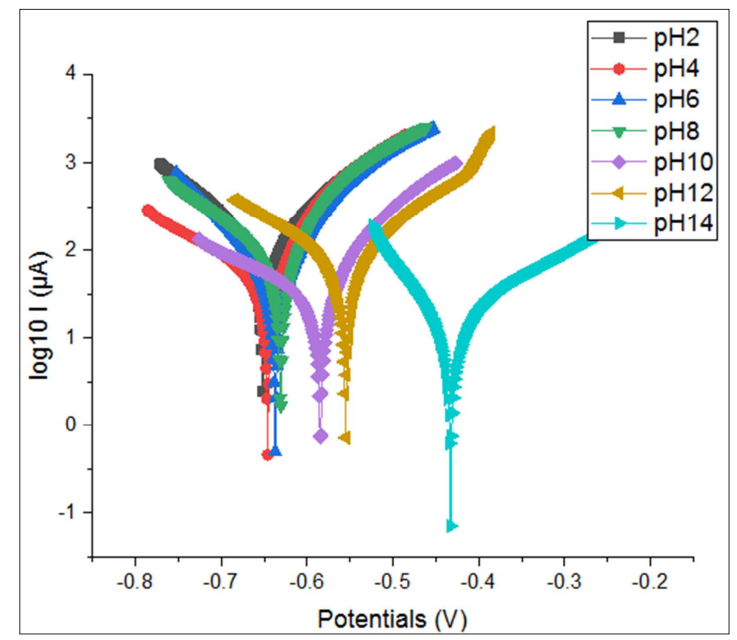

Figure 4. Tafel plot showing effect of $\mathrm{pH}$ variation of $1.0 \mathrm{M} \mathrm{HCl}$ solution in the presence of $1.0 \mathrm{~g}$ of methanol extract of Alchornea laxiflora leaves.

Table 2. Corrosion parameters for mild steel at various $\mathrm{pH}$ of the acidic solution at fixed concentration of methanol extract.

\begin{tabular}{|c|c|c|c|c|c|c|c|}
\hline pH & Conc. & $\mathbf{b}_{\mathbf{a}}$ & $\mathbf{b}_{\mathbf{c}}$ & $I_{\text {cor }}\left(\mathrm{A} / \mathrm{cm}^{2}\right)$ & $\mathbf{R}_{\mathrm{p}}$ & $\mathrm{CR}(\mathrm{mm} / \mathrm{y})$ & $\mathbf{E}_{\text {cor }}$ \\
\hline 2 & $1 \mathrm{~g} / \mathrm{L}$ & 0.334 & 366.149 & $4.38 \mathrm{E}-04$ & 201.6 & 5.069 & -0.652 \\
\hline 4 & $1 \mathrm{~g} / \mathrm{L}$ & 0.219 & 49.608 & 1.68 E-04 & 252.7 & 1.438 & -0.646 \\
\hline 6 & $1 \mathrm{~g} / \mathrm{L}$ & 0.105 & 7.447 & $1.05 \mathrm{E}-04$ & 331.3 & 1.229 & -0.637 \\
\hline 8 & $1 \mathrm{~g} / \mathrm{L}$ & 0.148 & 0.186 & $1.124-04$ & 346.8 & 1.121 & -0.631 \\
\hline 10 & $1 \mathrm{~g} / \mathrm{L}$ & 0.091 & 0.149 & 7.21 E-05 & 371.3 & 1.104 & -0.585 \\
\hline 12 & $1 \mathrm{~g} / \mathrm{L}$ & 0.084 & 0.148 & 6.37 E-05 & 665.6 & 0.763 & -0.555 \\
\hline 14 & $1 \mathrm{~g} / \mathrm{L}$ & 0.083 & 0.118 & 2.41 E-05 & 1452 & 0.279 & -0.433 \\
\hline
\end{tabular}

Moreso, a plot of the corrosion rate of the mild steel against $\mathrm{pH}$ (Figure 5), revealed that the corrosion rate of mild steel decreases with increase in $\mathrm{pH}$, and the value decreases sharply when the $\mathrm{pH}$ values was increased from 2 to 4 . At $\mathrm{pH}$ values of 4 to 10 , the difference in the corrosion rate of the mild steel was not significant but at $\mathrm{pH}$ higher than 10 , the corrosion rate of the mild steel decreased to the minimal.

The chemistry of this analysis is complicated, as at $\mathrm{pH}<4$ the corrosion reactions are:

$$
\mathrm{Fe} \rightarrow \mathrm{Fe}^{2+}+2 \mathrm{e}^{-}
$$

$$
2 \mathrm{H}^{+}+2 \mathrm{e}^{-} \rightarrow \mathrm{H}_{2}
$$

At higher $\mathrm{pH}$ (i.e $>4$ ) the corrosion rate is usually controlled by the reduction of $\mathrm{O}_{2}$ (under mass transport control) rather than $\mathrm{H}^{+}$reduction:

$$
\begin{gathered}
\mathrm{Fe} \rightarrow \mathrm{Fe}^{2+}+2 \mathrm{e}^{-} \\
2 \mathrm{H}_{2} \mathrm{O}+\mathrm{O}_{2}+4 \mathrm{e}^{-} \rightarrow 4 \mathrm{OH}^{-}
\end{gathered}
$$

This is often leads to a relatively constant corrosion rate at $4<\mathrm{pH}<10$. At higher $\mathrm{pH}$ values there is partial passivation of the surface with $\mathrm{Fe}_{2} \mathrm{O}_{3}$ and the corrosion rate falls. 


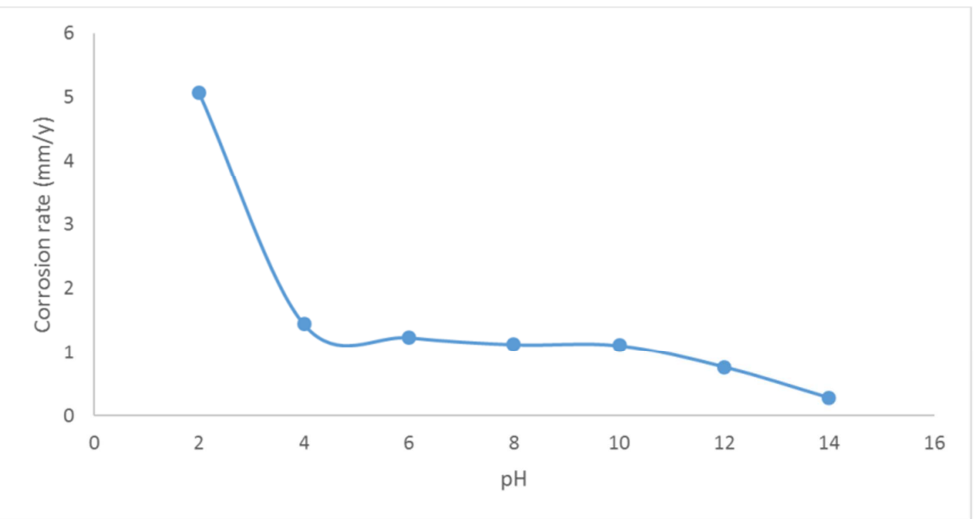

Figure 5. Plot of Corrosion rate of mild steel against $p H$ variation at fixed concentration of methanol extract of air dried Alchornea laxiflora leaves.

\subsubsection{Temperature Variation}

The potentiodynamic polarization curves for fixed concentration of methanol extract of Alchornea laxiflora leaves extract in $1.0 \mathrm{M} \mathrm{HCl}$ at different temperature on mild steel are shown in Figure 6. Polarization parameters such as corrosion potentials $\left(\mathrm{E}_{\mathrm{cor}}\right)$, corrosion current potent $\left(\mathrm{I}_{\mathrm{cor}}\right)$, anodic Tafel slope (ba), cathodic Tafel slope (bc) and polarization resistance at different temperature and fixed concentration are listed in Table 3. From the table it was observed that the polarization resistance of the mild steel was reducing with increase in temperature and the corrosion rate was increasing with increase in temperature. The decrease in polarization resistance and increase in corrosion rate of the mild steel with increase in temperature can be attributed to the desorption of the phytochemical constituents of the extract from the surface of the mild steel which gave room for an increase in the corrosion rate of the mild steel with increase in temperature [44].

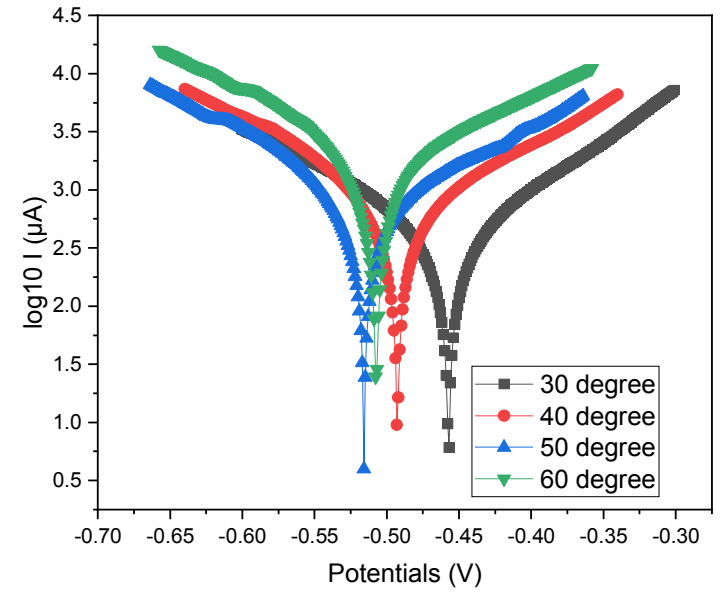

Figure 6. Tafel plots of mild steel specimen in $1.0 \mathrm{M} \mathrm{HCl}$ at different temperature and fixed concentration of methanol extract of Alchornea laxiflora leaves.

Table 3. Corrosion parameters for mild steel in 1.0M HCl at different temperature and fixed concentration of methanol extract.

\begin{tabular}{|c|c|c|c|c|c|c|c|c|}
\hline Temp. (oC) & Inh. Conc. & $\mathrm{Ba}(\mathrm{v} / \mathrm{dec})$ & $\mathrm{Bc}(\mathrm{v} / \mathrm{dec})$ & I Cor $\left(\mathrm{Acm}^{2}{ }^{2}\right)$ & $\mathbf{R}_{\mathrm{P}}(\mathrm{ohms})$ & $\mathbf{m m} / \mathbf{y}$ & $\mathrm{g} / \mathrm{h} / \mathrm{cm}^{2}$ & $\mathbf{E}_{\text {Cor. }}$ \\
\hline 30 & $1 \mathrm{~g} / \mathrm{L}$ & 0.145 & 0.171 & $5.36 \mathrm{E}-04$ & 66.98 & 6.203 & 0.00056 & -0.457 \\
\hline 40 & $1 \mathrm{~g} / \mathrm{L}$ & 0.332 & 0.176 & 0.001 & 39.7 & 15.32 & 0.00138 & -0.493 \\
\hline 50 & $1 \mathrm{~g} / \mathrm{L}$ & 2.484 & 0.288 & 0.003 & 35.59 & 38.34 & 0.00345 & -0.516 \\
\hline 60 & $1 \mathrm{~g} / \mathrm{L}$ & 0.342 & 0.193 & 0.003 & 17.24 & 39.8 & 0.00358 & -0.508 \\
\hline
\end{tabular}

\subsubsection{Concentration Studies}

The polarization studies of mild steel were carried out in $1.0 \mathrm{M} \mathrm{HCl}$ in the presence and absence of different concentration of methanol extract of Alchornea laxiflora leave at room temperature. The Tafel plot and the polarization parameters such as corrosion current densities $\left(\mathrm{I}_{\mathrm{cor}}\right)$, Corrosion potentials $\left(\mathrm{E}_{\mathrm{cor}}\right)$, cathodic Tafel slope $(\beta \mathrm{c})$, anodic Tafel slope $(\beta \mathrm{a})$, polarization resistance $(\mathrm{Rp})$, corrosion rate and the percentage inhibition efficiency $\eta_{\mathrm{T}}(\%)$ calculated by using equation 1 during the dissolution of the mild steel in the acidic medium in the absence and presence of the plant extract are shown in Figure 7 and Table 4 respectively.

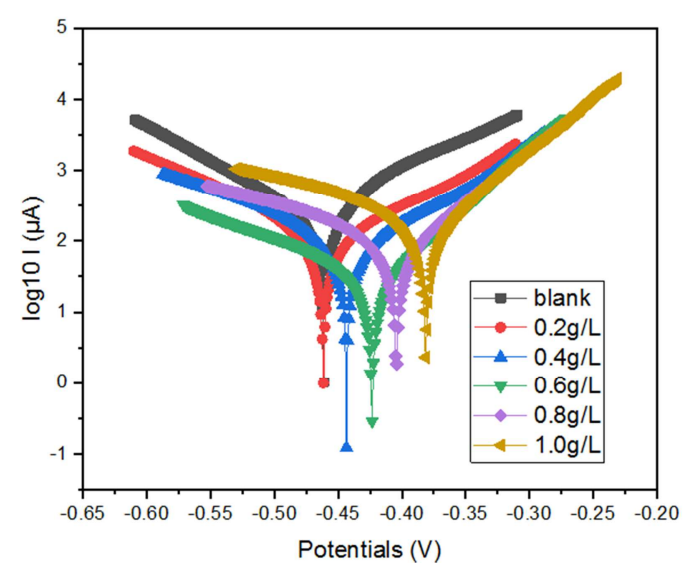

Figure 7. Polarization curve for mild steel in 1.0M $\mathrm{HCl}$ solution in the absence and presence of various concentration of methanol extract of air dried Alchornea laxiflora leaves. 


$$
\eta_{\mathrm{T}}(\%)=\frac{I_{\text {cor }}^{o}-I_{\text {cor }}}{I_{\text {cor }}^{o}}
$$

Where $I_{\text {cor }}^{o}$ and $I_{\text {cor }}$ are the corrosion current densities without and with inhibitor, respectively. From the result there was a decrease in the corrosion current density as the concentration of the extract increases and a lowest value of $\mathrm{I}_{\text {cor }}$ was observed for the inhibitor solution of $1.0 \mathrm{~g} / \mathrm{L}$ which exhibit a maximum inhibition value of $93.62 \%$. Moreso the values of the polarization resistance of the mild steel increase with increase in concentration of the inhibitor. In electrochemical measurement, if the shift of $\mathrm{E}_{\text {cor }}$ is $>85 \mathrm{mV}$ with respect to $\mathrm{E}_{\text {cor }}$ of uninhibited acid solution, then the inhibitor can be termed as cathodic or anodic inhibitor [45-47]. From this research, the maximum shift of $\mathrm{E}_{\text {cor }}$ is $80 \mathrm{mV}$, which implies that the methanol extract of the air dried Alchornea laxiflora leaves acts as a mixed inhibitor for mild steel specimens in $1.0 \mathrm{M} \mathrm{HCl}$.

Table 4. Corrosion parameters for mild steel in the absence and presence of different concentration of methanol extract of Alchornea laxiflora leave extract at room temperature.

\begin{tabular}{|c|c|c|c|c|c|c|c|c|}
\hline Conc. (g/L) & $\mathrm{Ba}(\mathrm{v} / \mathrm{dec})$ & $\operatorname{Bc}(\mathrm{v} / \mathrm{dec})$ & $\operatorname{Icor}\left(\mathbf{A} / \mathrm{cm}^{2}\right)$ & $P_{R}($ ohms $)$ & $\mathrm{CR}(\mathrm{mm} / \mathrm{y})$ & $\mathrm{CR}(\mathrm{g} / \mathrm{h} / \mathrm{cm})$ & $\mathbf{E}_{\text {cor }}$ & I.E (\%) \\
\hline Blank & 0.148 & 0.752 & $7.11 \mathrm{E}-04$ & 83.52 & 8.23 & 0.00074 & 0.462 & - \\
\hline 0.2 & 0.143 & 0.644 & 2.53 E-04 & 122.2 & 4.93 & 0.00044 & 0.462 & 64.41 \\
\hline 0.4 & 0.126 & 0.152 & 1.74 E-04 & 231.6 & 2.018 & 0.00018 & 0.444 & 75.53 \\
\hline 0.6 & 0.111 & 0.141 & 1.33 E-04 & 606.3 & 1.539 & 0.00014 & 0.423 & 81.29 \\
\hline 0.8 & 0.103 & 0.122 & 7.43 E-05 & 654.7 & 0.859 & 0.00008 & 0.404 & 89.55 \\
\hline 1.0 & 0.100 & 0.105 & 4.54 E-05 & 821.4 & 0.525 & 0.00003 & 0.382 & 93.62 \\
\hline
\end{tabular}

\section{Conclusion}

The green inhibitor of air dried Alchornea laxiflora was extracted using methanol by maceration method. The mode of storage and the shelf life of the extract was studied using weight loss measurement and the effect of $\mathrm{pH}$, temperature and concentration variation of the acidic medium on mild steel was carried using electrochemical measurement. The results obtained indicated that the methanol extract is most active when it was stored at room temperature and below. The shelf life study revealed that the extract exhibited a maximum inhibition within the sixty days of its production. The result of the $\mathrm{pH}$, temperature and concentration variation of the acidic medium on mild steel revealed that the corrosion rate of the mild steel decreases with increase in $\mathrm{pH}$, decrease in temperature and increase in concentration of the extract in acidic medium.

\section{Recommendations}

The use of methanol extract of Alchornea laxiflora leaves in Corrosion prevention should be encouraged by putting the following into consideration:

Storing the extract at room temperature after its production.

The extract is recommended for use within 60 days of its production.

With respect to the results obtained during electrochemical measurement experiment, It's recommended that the use of the extract in corrosion prevention, should be carried out at higher $\mathrm{pH}$ and lower temperature of the acidic media together with high concentration of the extract.

\section{Conflict of Interest}

We declare that we have no conflict of interest.

\section{Acknowledgements}

The authors are grateful to Professor Roy Sudipta and Dr. Todd Green, all from University of Strathclyde, Glasgow, United Kingdom, for their assistance and useful advice offered during the experiment.

\section{References}

[1] H. K. Gerhardus, P. H. MichielBrongers and G. Neil Thompsom, Corrosion Costs and Preventive Strategies in the United States" NACE International Publication No. FHWARD-01-156 Technologies Laboratories, Inc., Dublin, Ohio.

[2] M. Benabdellah, M. Benkaddour, B. Hammouti, M. Bendahhouand A. Aouniti, Appl. Surf. Sci., 2006, 252, 62126217.

[3] P. B. Raja, M. G. Sethuraman, Mater. Lett. 2008, 62, 113-116.

[4] L. Wang, J. Pu, H. Luo. Corros. Sci. 2003, 45, 677-683.

[5] A. Y. EL-Etre. Corros. Sci., 1998, 40, 1845-1850.

[6] I. Radojcic, K. Berkovic, S. Kovac, J. Vorkapic-Furac. Corros. Sci., 2008, 50, 1498-1504.

[7] Z. Ahmad, Principles of Corrosion Engineering and Corrosion Control1st Edition Butterworth-Heinemann, 2006, eBook ISBN: 9780080480336, Paperback BN: 9780750659246, 672.

[8] P. R. Roberge. Handbook of Corrosion Engineering, McGrawHill, New York, 2000.

[9] S. A. Ali, H. A. Al-Muallem, S. U. Rahman, M. T. Saeed. Corros. Sci., 2008, 50, 3070-377.

[10] B. Mernari, H. El Attari, M. Traisnel, F. Bentiss, M. Lagrenee. Corros. Sci., 1998, 40, 391-399.

[11] M. El Achouri, S. Kertit, H. M. Gouttaya, B. Nciri, Y. Bensouda, L. Perez, M. R. Infante, K. ElKacemi, Prog. Org. Coat. 2001, 43, 267-273. 
[12] S. A. Abd El Maksoud, Corros. Sci., 2002, 44, 803-813.

[13] M. Abdallah, Corros. Sci. 2002, 44, 717-728.

[14] K. F. Khaled, Electrochim. Acta. 2003, 48, 2493-2503.

[15] M. Behpour, S. M. Ghoreishi, N. Soltani, M. Salavati-Niasari, Corros. Sci. 2009, 51, 1073-1082.

[16] G. Kardas, R. Solmaz, Corros. Rev. 2006, 24, 151-171.

[17] R. Solmaz, G. Kardas, B. Yazici, M. Erbil, Prot. Met. 2007, 5, 476-482.

[18] R. Solmaz, G. Kardas, B. Yazıcı, M. Erbil, Prot. Met. 2005, $41,581-585$.

[19] H. Keles, M. Keles , I. Dehri, O. Serindag, Osman Serindag, Colloid Surf. A. 2008, 320, 138-145.

[20] I. B. Obot, N. O. Obi-Egbedi, S. A. Umoren, Int. J. Electrochem. Sci. 2009, 4, 863.

[21] S. Kertit, B. Hammouti, Appl. Surf. Sci. 1996, 93, 59-66.

[22] O. K. Abiola, Corros. Sci. 2006, 48, 3078-3090.

[23] J. O. M. Bockris, A. K. N. Reddy, Modern Electrochemistry, Plenum Publishing Corporation, New York, 1976, 2.

[24] T. A. Soylev, M. G. Richardson, Constr. Build. Mater. 2008, 22, 609-622.

[25] R. Solmaza, E. Altunbas, G. zaKardas, Materials Chemistry and Physics, 2011, 125, 796-801.

[26] A. R. Afidah, E. Rocca, J. Steinmetz, M. J. Kassim, Corros. Sci. 2008, 50, 1546-1550.

[27] A. Ostovari, S. M. Hoseinieh, M. Peikari, S. R. Shadizadeh, S. J. Hashemi, Corros. Sci. 2009, 51, 1935-1949.

[28] E. F. Olasehinde, J. K. Ogunjobi, O. M. Akinlosotu, S. A. Omogbehin "Investigation of the Inhibitive Properties of Alchornealaxiflora leaves on the Corrosion of Mild Steel in $\mathrm{HCl}$ : Thermodynamics and Kinetic Study" Journal of American Science 2015, 11 (1s), 32-39.

[29] U. J. Ahile, J. A. Gbertyo, J. S. Anzene, J. O. Ajegi and E. J. Oche. Evaluation of the Inhibitive Properties and Adsorptive Parameters of Ethanol Leaf Extract of Mucuna Pruriens for the Corrosion Inhibition of Aluminium In $2 \mathrm{M} \mathrm{H}_{2} \mathrm{SO}_{4}$, International Journal of Innovative Science, Engineering \& Technology, 2014, Vol. 1 Issue 6, August 2014.

[30] Yuli Yetri, Emriadi, Novesar Jamarun, and Gunawarman: Corrosion Inhibition Efficiency of Mild Steel in Hydrocloric Acid by Adding Theobroma Cacao Peel Extract" International Conference on Biological, Chemical and Environmental Sciences (BCES-2014) June 14-15, 2014 Penang (Malaysia).

[31] I. Ahamad, M. A. Quraishi Mebendazole: New and efficient corrosion inhibitor for mild steel in acid medium. Corrosion Science, 2010; 52 (2), 651-656.

[32] S. K Shukla, A. K Singh, I. Ahamad, M. A. Quraishi. A. Streptomycin: A commercially available drug as corrosion inhibitor for mild steel in hydrochloric acid solution. Mater. Lett. 2009; 63 (9-10), 819-822.

[33] Verma C, Quraishi MA, Ebenso EE. Electrochemical Studies of 2-amino-1, 9-dihydro-9- ((2-hydroxyethoxy) methyl)-6Hpurin-6-one as Green Corrosion Inhibitor for Mild Steel in 1.0
$\mathrm{M}$ hydrochloric Acid Solution. International journal of Eectrochemical Science, 2013; 8 (5), 7401-7413.

[34] Oluwafemi L. Adebayo, Emmanuel F. Olasehinde, Labunmi Lajide and Daniel T. Oloruntoba: Comparative analysis of air dried Alchornealaxiflora leaf extracted with different solvents on corrosion inhibition efficiency of mild steel in acidic media. International Journal of Research in Engineering and Innovation, 2019, 3, 208-216.

[35] B. S. Davi and Rajandran, S. "Influence of garlic extract on the inhibition efficiency of trisodium citrate-Zn2+ system, International Journal of Chemical Science and Technology, 2011, 1, 79-87.

[36] P. C. Okafor, V. I. Osabor and E. E. Ebenso" Eco-friendly corrosion inhibitor: Inhibitive action of ethanol extracts of Garcinia kola for the corrosion of mild steel in $\mathrm{H}_{2} \mathrm{SO}_{4}$ solutions, Pigment and Resin Technology, 2007, 35 (5), 299-305.

[37] E. E. Oguzie "Influence of halid ions on the inhibitive effect of Congo red dye on the corrosion of mild steel in sulphuric acid solution, Material Chemistry and Physics, vol., 2005, 87 (1), 212-217.

[38] J. B. Harborne "Phytochemical Methods: A Guide to Modern Techniques of plant Analysis. Chapman \& Hall Ltd, London, (1973), pp 278.

[39] D. E. Okwu" Evaluation of the Chemical Composition of indigenous species and flavouring agents. Global Journal of Pure and Applied Science, 2001, 7 (3), 455-459.

[40] T. N. Rahilla, S. Rukh and A. A. Zaidi Phytochemical Screening of Medicinal Plants belonging to Euphoribiaceae Pak, Veterinary Journal, 1994, 14, 160-2.

[41] A. Sofowara, Medicinal Plants and Traditional Medicine in Africa, Ibadan, Nigeria, Spectrum Book Ltd., 1993, pp. 289.

[42] C. L. Del-Toro-Sánchez, M. Gutiérrez-Lomelí, E. LugoCervantes, et al., "Storage Effect on Phenols and on the Antioxidant Activity of Extracts from Anemopsiscalifornica and Inhibition of Elastase Enzyme," Journal of Chemistry, 2015, vol. 2015, Article ID 602136, 8 pages.

[43] R. Rajalakshmi and A. S. Safina: Staminate Flower of Cocos Nucifera as Green Inhibitor for Mild Steel in $\mathrm{HCl}$ Medium, $E$ Journal of Chemistry, 2012, 9 (3), 1632-1644.

[44] Xi-lan Jiang, Chuan Lai, Zhen Xiang, Ya-fei Yang, Bang-long Tan, Zhong-qiu Long, Lin- peng Liu, Yun-tianGu, Wen-jian Yang, Xia Chen: Study on the Extract of Raphanus Sativus L as Green Corrosion Inhibitor for Steel in $\mathrm{HCl}$ Solution, int. J. Electrochem. Sci., 2018, 133224-3234, doi: 10.20964/2018.04/16.

[45] Li, Q. He, S. Zhang, C. Pei and B. Hou, Some new triazole derivatives as inhibitor for mild steel corrosion in acidic medium, journal of Applied Electrochemistry, 2008, 38 (3), 289-295.

[46] H. Fu, Synergism between red tetrazolium and uracil on the corrosion of cold rolled steel in $\mathrm{H}_{2} \mathrm{SO}_{4}$ solution, Corrosion science, 2009, 51 (6), 1344-1355.

[47] E. S. Ferreira, C. Giacomelli, F. C. Giacomelli and A. Spinell, Evaluation of the inhibitor effect of L-ascorbic acid on the corrosion of mild steel. Material Chemistry and Physics, 2004, 83 (1), 129-134. 